DENTAL NURSES HIT THE CATWALK FOR CHARITY

Shrewsbury and Stafford-based Oracle Dental Clinics raised more than $£ 400$ for Severn Hospice by staging their own glitzy Charity Fashion Gala earlier this year.

The special event, held at Lord Hill Hotel, Shrewsbury, saw more than 60 invited guests from the region's dental community enjoy the chance to pick up top tips from a number of fashion and beauty consultants, as well as watching a fashion show where Oracle Dental Clinics staff donned some of the latest fashions and accessories and took to the catwalk.

'Our staff were incredibly keen to take their chance to be a "model for the day", said Michelle Cutler, Group Manager of Oracle Dental Clinics. 'Some have already been asking if we can make it a regular event.'

'We'd like to thank everyone at Oracle Dental Clinics for putting on the fashion show, and the guests for their generosity, said Lucy Proctor, Severn Hospice's Community Fundraising Manager. 'The funds raised will be a huge help to our ongoing work and will make a real difference to supporting local people who are living with complex and progressive illnesses.

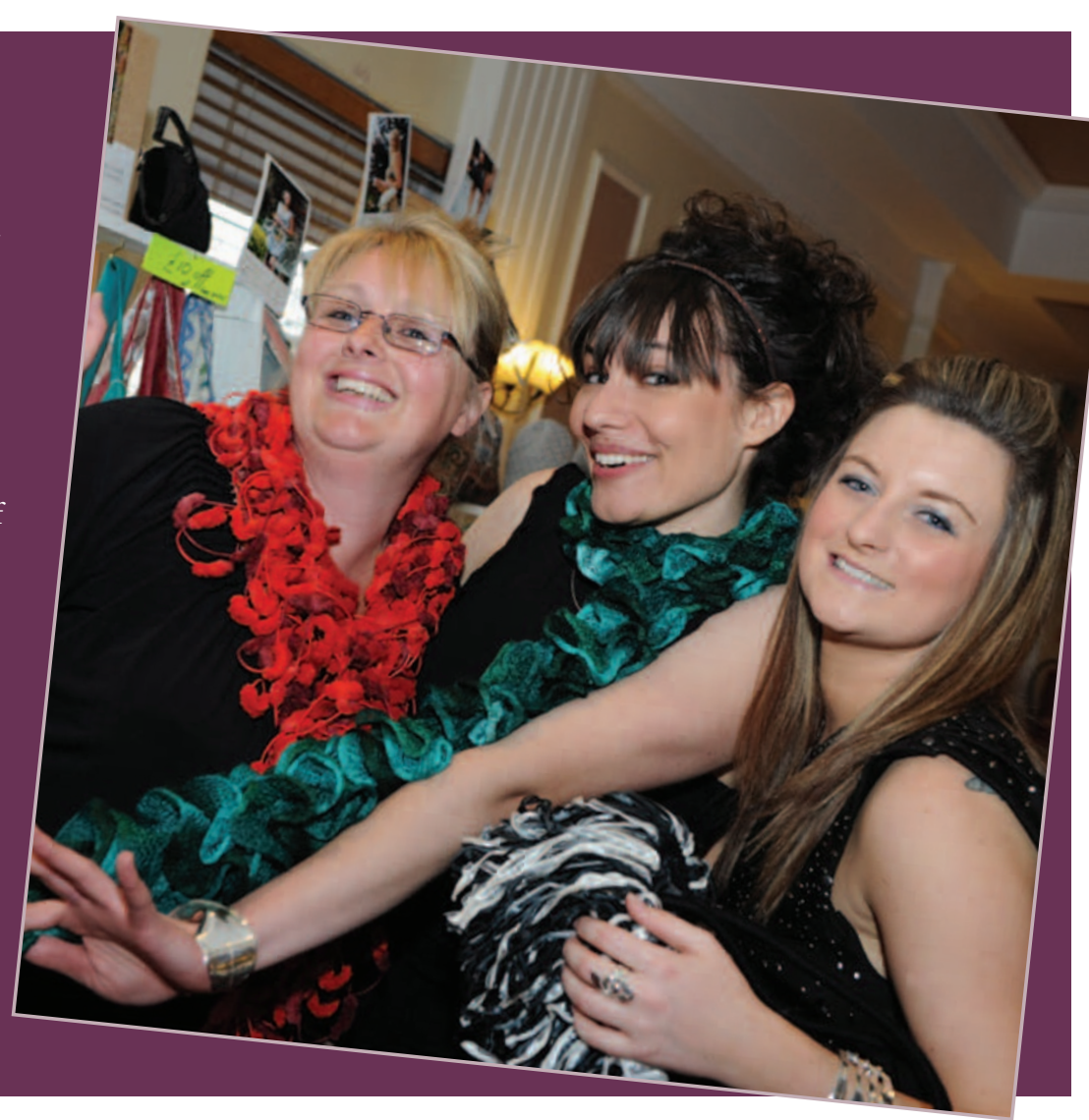

\title{
NEW RESOURCE WILL AID PATIENT TOOTHPASTE CHOICE
}

\section{TODDLER NUTRITION MUST BE PRIORITISED}

The Infant \& Toddler Forum experts in child health, nutrition and development - is stepping up its work to encourage wider recognition and adoption of its Ten steps for healthy toddlers, launched last year to address the lack of simple, consistent guidance on toddler eating habits.

The Ten steps are an easy-to-use guide on what food to offer, what eating behaviours to encourage and how best to manage mealtimes. Endorsed by the Pre-school Learning Alliance, Child

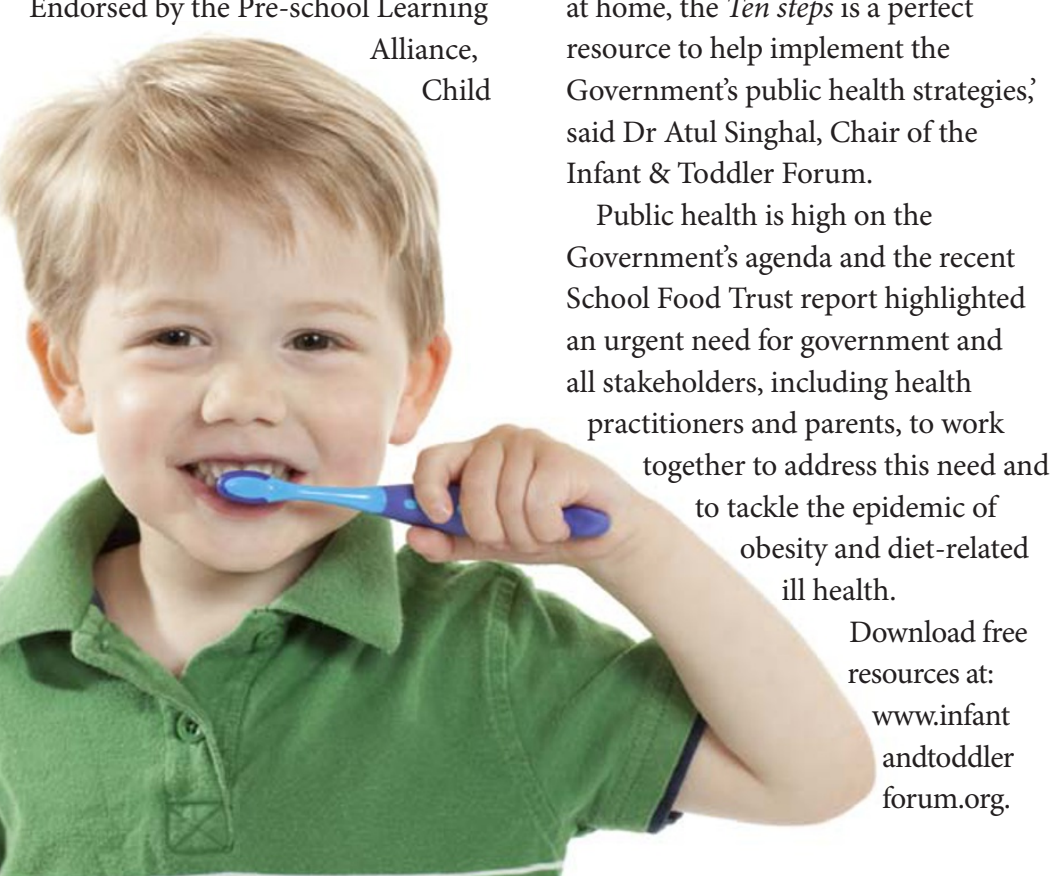

Forum and the British Dental Health Foundation (BDHF), the Ten steps are designed to encourage positive changes to toddler feeding with small easy actions. The BDHF were also involved in the writing and approval of one of the Infant \& Toddler Forum's factsheets, Protecting toddlers from dental decay.

'As well as being a simple, extremely useful tool for those feeding toddlers at home, the Ten steps is a perfect resource to help implement the said Dr Atul Singhal, Chair of the a Toddler Forum. an urgent need for government and all stakeholders, including health practitioners and parents, to work ther to address this need and besity and diet-related alth.
A new online resource will help dental professionals care for patients with adverse effects caused by their toothpaste.

The UK Medicines Information Service has produced a document listing toothpastes widely available in the UK and the excipients they contain. Toothpastes contain a large number of excipients including fluoride, abrasives, detergents, binding agents, humectants, preservatives, colouring agents, antiseptics and flavourings. Some of these excipients, most commonly flavourings, cause adverse oral reactions such as cheilitis (due to allergic or irritant contact dermatitis), peri-oral eczema, stomatitis, lichenoid reactions, burning mouth syndrome, loss of taste, and systemic adverse effects such as anaphylaxis and rhinitis. Tartar-control toothpastes containing pyrophosphates can be a particular problem as they contain higher concentrations of flavourings and detergents.

For patients who experience adverse effects thought to be due to their toothpaste, changing to another product that does not contain the suspected excipient can completely resolve symptoms within a few weeks or months.

The document will be updated every two years and is freely available on the NHS Evidence and UK Medicines Information website.

To go straight to the document, visit www.nelm.nhs uk/en/NeLM-Area/Evidence/Medicines-Q-A/What-

are-the-excipients-in-toothpastes/ 